\title{
Energy Efficient Lighting in the Residences of Staff of the University of Education, Winneba
}

\author{
Anderson, I. $\mathbf{K}$. \\ Department of Science Education, UEW, Winneba, Ghana. \\ and \\ Boateng-Ennimful, E. \\ Department of Science Education, UEW, Winneba, Ghana.
}

\begin{abstract}
It is estimated that $15 \%$ of electric power production is used for lighting consumption in Ghana. This figure is likely to increase as the country develops. There is no doubt therefore, that improving the energy efficiency of lighting in Ghana could have a great impact on Ghana's energy consumption, and subsequently, on the economy. The study is to investigate the level to which energy-efficient lighting systems are being used in some selected bungalows at the University of Education, Winneba, in Ghana. Forty bungalows were selected for the survey. A questionnaire was used to ascertain information on compact fluorescent lamp (CFL) as an energy-efficient lighting system. The results of the study show that even though academics in the university have received information about the use of CFLs as a way of saving energy, very few show interest in their use. It is inferred that lamp prices could be a more important influence on consumer's choice of efficient lamp than the cost of electricity. Market barriers, such as cost of and fundamental problems with the use of CFLs are discussed along with appropriate remedies.
\end{abstract}

\section{Introduction}

Energy production and use impose significant economic and environmental costs on Ghana. Given the ever-growing population and standard of living in the country, the current electricity demand-and-supply relationship cannot be sustained much longer. The combination of growth in population and building of infrastructure will cause for example lighting demand to grow quickly, probably faster than overall electricity demand.

One area in which consumption of electricity is prominent and in high demand is household lighting. General incandescent lamp and linear fluorescent lamptypes are most popular lighting fixtures in Ghana. However the low-priced, luminous and popular incandescent lamps consume a lot of electrical energy due to the high wattage, and operate at high temperatures resulting in increase 
in the ambient temperature of a room. The minimum temperature of $121^{\circ} \mathrm{C}$ is typically associated with 100-watts incandescent lamp of tungsten filament type (Mills, 1996). Linear fluorescent lamp also gives significant inefficiency. Market survey on Incandescent lamps indicates that approximately two million of these lamps are sold each year in the country. Considering its high level of inefficiency, it implies that there is a lot of wastage in the system. This in no small way contributes to a lot of wastage in terms of electricity consumption. There is therefore the need to find alternative ways of household lighting to conserve energy.

An alternative lamp type called compact fluorescent lamp (CFL) is recommended. This lamp-type offers benefits in terms of energy cost-control. There is fire-safety improvement on the highly efficient compact fluorescent lamps (Page et al. 1997). The maximum temperature of the compact fluorescent lamp is approximately $60^{\circ} \mathrm{C}$ far below that of the incandescent lamp. It must be noted that energy-saving alternatives such as compact fluorescent lamps actually pay for themselves many times over in terms of energy cost savings (Mills, 1996). Table 1 shows the lamp performance standard indicators.

Table 1 Lamp performance standard indicators

\begin{tabular}{|l|l|l|}
\hline Lamp type life (hours) & Wattage & Efficacy (lumens/W) \\
\hline General incandescent (100-1000) & $15-100$ & $7-18$ \\
\hline Linear fluorescent (1000-3000) & $6-125$ & $25-40$ \\
\hline Compact fluorescent (3000-5000) & $4-28$ & $40-65$ \\
\hline \multicolumn{2}{|c}{ (Courtesy: G.F. Min et al) } \\
\hline
\end{tabular}

( Courtesy: G.F. Min et al)

According to Johansson et al (1989), there is a large potential for improving the efficiency of lighting and all other major electricity end uses at a cost less than that of building new power plants. However continuing shortfall between electricity demand-and-supply, the escalating cost of building new power plants as well as the competing needs for investment capital from donor agencies are just some of the obvious reasons why Ghana is ripe for improved energy efficiency in lighting and other end use areas.

Moreover, power shortages are attributable in part to peak demands caused by lighting and air-conditioning in the major cities. The basic problem is the means to improve efficiency. Lack of clear direction and comprehensive policy from the central and local governments and lack of incentives for energy efficient products mitigate the need for energy efficient lighting. Looking at the economic base of Ghanaians and the high cost of energy efficient lighting systems, typical Ghanaian consumers prefer lighting systems that are less expensive. However these less expensive systems are inefficient resulting in energy wastage. Therefore, there is a very clear indication that the Ghanaian consumer is more interested in saving money and has either very little interest or no knowledge at all about issues on energy conservation. Further more because the price of electricity is not so high, the average Ghanaian does not see the need to buy high priced CFLs for the purpose of conserving energy. 
According to Bartlett (1993), those who patronise the use of CFLs as well as those who do not are motivated by a number of factors including economic and non-economic factors. He further observes that these factors could help shape consumer attitudes, and that educating the people on environmental protection through energy saving devices is often the most important non-economic motivation. Brond (1990), has also observed that, generally, studies carried out in other places such as France and Sweden indicate that merely giving information on the use of CFLs as energy saving device is not as effective as providing financial incentives such as lowering the cost of CFLs.

\section{Methodology}

The study considered all the staff bungalows on the three campuses of the University. However, forty (40) living bungalows on the North campus were purposively sampled for the study. A questionnaire was distributed to the occupants of each of the selected bungalows. The questionnaire was used to ascertain the following:

- Level of knowledge of CFL.

- Level of patronage of CFL.

- Quality of lighting provided by CFL.

- Level of acceptance of the amount of light provided by CFL.

- Cost of CFL as compared to incandescent.

- Degree of economic motivation.

Responses to the questionnaire were converted into percentages.

\section{Results}

\section{Responses to the questions on CFL}

Responses made to items in the questionnaire are summarised in Table 2. The table shows that $82.5 \%$ of the respondents have obtained information and therefore have knowledge about CFLs. However, when it comes to the information or knowledge about CFLs as energy-saving device, the number reduces to about $72 \%$. It means that though a lot of people have some information about CFLs, some are not aware of the purpose CFLs serve, that is, they are not aware that the essence of CFLs is to save energy.

It is interesting to note that even though a lot of people $(82 \%)$ have knowledge and information about CFL, when it comes to their intentions or plans to replace some of their lamps with CFLs, the number drops to $71 \%$. Taking into consideration that about as many as $72 \%$ have knowledge about CFLs as energy saving device, one would have expected that almost the same number would be interested in buying additional CFLs. However, the number drops to $56 \%$. It could also be observed that only half of the population have received some form of promotional literature on energy-efficient lighting such as CFLs. When it comes to quality level of illumination provided by CFLs, about $82 \%$ affirmed that they were satisfied with the light provided. One would have expected that the use of such energy-saving device would reflect on the 
electricity bill in such a way that cost would go down. However, only $45 \%$ indicated that there was a decrease in electricity bill.

Table 2: The responses given to questions on CFL.

\begin{tabular}{|c|c|c|c|c|}
\hline Item & Yes & $\%$ & No & $\%$ \\
\hline Knowledge or information about energy-efficient lamp & 33 & 82.5 & 7 & 17.5 \\
\hline Knowledge about CFL as energy saving device & 29 & 72.5 & 11 & 27.5 \\
\hline Plans to replace other lamps with CFLs & 27 & 71.0 & 11 & 29.0 \\
\hline Future plans to buy additional CFLs & 9 & 56.0 & 7 & 44.0 \\
\hline $\begin{array}{l}\text { Receiving promotional literature or information on } \\
\text { energy-efficient lighting }\end{array}$ & 21 & 52.5 & 19 & 47.5 \\
\hline Satisfaction with amount of light provided byCFL & 9 & 82.0 & 2 & 18.0 \\
\hline Significant decrease in electricity bill & 5 & 45.0 & 6 & 55.0 \\
\hline $\begin{array}{l}\text { Payment of cost of CFLs by cash directly and not } \\
\text { through electricity bill }\end{array}$ & 23 & 69.7 & 10 & 30.3 \\
\hline
\end{tabular}

When it comes to the payment of the cost of CFLs, $69.7 \%$ opted to pay by cash directly while $30.3 \%$ wanted to pay gradually through electricity bills. Several other reasons were to each of the following categories:

a) Direct payment by cash:

- $\quad$ Paying monthly bills could be unreliable. Thus there could be over payment.

- $\quad$ Not interested in credit buying.

- Inability to cope with large bills.

- Cost of CFLs is manageable and therefore there is no need to spread the payment through the electricity bills.

- $\quad$ Possible regular increase in price due to unstable exchange rate.

- Electricity bills being subject to manipulation and sometimes questionable.

- $\quad$ Preference for the true reflection of electricity consumption on the bills.

b) Payment gradually through electricity bills:

- $\quad$ Cost of CFL is high and therefore supplying it on credit basis and deducting gradually through electricity is better.

- $\quad$ Avoidance of fraud through the purchase of the CFL. 
- $\quad$ Easier to make payment gradually via electricity bills.

\section{Light lamps installed in bungalows}

Table 3 shows the number of light lamps installed in the bungalows. It shows that only $3 \%$ of the population use CFLs whiles $52 \%$ and $45 \%$ use incandescent and fluorescent lamps respectively. It is quite striking to observe that as many as $72 \%$ (table 1 ) know that CFLs serve as energy-saving device. However when it comes to the use, only $3 \%$ are interested. This may be due to high cost of CFLs.

Table 3 Light lamps installed in the bungalows

\begin{tabular}{lcc}
\hline Type of light lamp & Frequency & $\%$ \\
\hline Compact fluorescent & 13 & 3 \\
Incandescent & 225 & 52 \\
Fluorescent & 194 & 45 \\
\hline
\end{tabular}

The cost of a CFL at the Electricity Company of Ghana is $\$ 11,200$, while at the open market it costs as much as $\$ 28,000$. The cost of incandescent lamp (tungsten filament) is however, as low as $\$ 2,500$. The vast difference between the cost of CFL and incandescent lamp may contribute, to a large extent, to the low patronage of CFLs. It can be seen clearly that the immediate concern of people is to save money and not energy. Respondents also indicated that despite the good quality of light from CFLs, it is short-lived, if it is at a point where there is intermittent on- and-off regulation of electricity.

\section{Incandescent lamps used in bungalows}

Table 4 shows the number of 40watts and 60watts incandescent lamps used in the bungalows.

Table 4 Incandescent lamps used in bungalows

\begin{tabular}{lll}
\hline Wattage & Number & \% \\
\hline 40 & 10 & 29.4 \\
60 & 24 & 70.6 \\
\hline
\end{tabular}

It was also observed that 60watts incandescent lamps were the most commonly used. This could be attributed to the quality or intensity of light as compared to the 40watts lamps.

\section{Reasons for patronising or not patronising CFLs}

Tables 5 shows the reasons why some of the respondents patronized CFLs while Tables 6 shows why others did not. It was observed from table $3 a$ that more people $(23.0 \%)$ patronise CFL for energy saving purposes while about 20\% use CFLs for the purpose of saving money. This seems to contradict the previous observation, which indicates that 
more people patronise CFLs to save money (table 4a). This observation is quite interesting. It has already been observed and stated that as many as $82 \%$ of the respondents have knowledge of the use of CFL as energy-saving device (Ref. table1). It is therefore not surprising that such a reason for patronising CFL tops the list. However, when it comes to practical use of it, that is the actual use of the lamps, a lot of people will shrink from it because of the cost involved.

Table 5 Reasons for patronising CFLs

\begin{tabular}{lcc}
\hline \multicolumn{1}{c}{ Reason } & Frequency & \% \\
\hline To save energy & 18 & 23.0 \\
To save money & 16 & 20.5 \\
Lamp last longer & 13 & 16.7 \\
Desire to use a new lamp & 1 & 1.3 \\
Provide quality lighting & 9 & 11.5 \\
Lower temperature and does not make & 13 & 16.7 \\
surrounding warm & & \\
Concern for the effect of high energy & & 10.3 \\
consumption on environment & 8 & \\
\hline
\end{tabular}

Table 6 Reasons for not patronising

\begin{tabular}{lcc}
\hline \multicolumn{1}{c}{ Reason } & Frequency & \% \\
\hline Not interested & 1 & 5.1 \\
Do not see any reason & 2 & 5.1 \\
It is too expensive & 7 & 18.0 \\
There is no financial incentive & 2 & 5.1 \\
There is inadequate information on use of CFLs & 14 & 35.9 \\
Inability to find the right CFL & 8 & 23.1 \\
Issues on energy consumption are not quite clear & 3 & 7.7 \\
\hline
\end{tabular}

The reasons for not partronising the CFL seem to confirm the above observations. This is in agreement with the observation made by Brond (1990) that generally, studies carried out in other places indicate that merely giving information on the use of CFLs as energy saving device is not as effective as providing financial incentives such as lowering the cost of CFLs.

As much as $18 \%$ (table $3 \mathrm{~b}$ ) mentioned the cost as one of the reasons for not patronising, that is CFLs are too expensive. Again, 35.9\% said there is inadequate information on the use of CFLs. Thus, even though a lot of people have information on the CFL as energy-saving device, they have very little knowledge about its use and the problems or benefits associated with it. 
Further more, about $23.1 \%$ mentioned that they could not find the "right" CFL. Perhaps the idea here is that they are not able to find CFL which can last quite a long time considering the intermittent on- and- off regulation of electricity or the appropriate wattage to buy.

\section{Analysis of electricity consumption between Incandescent and CFL.}

The responses showed that an average time for use of lamps was $\mathbf{9}$ hours per day and the average light points for each bungalow was 13points. The calculations are therefore based on an average of $\mathbf{9}$ hours per day of use of lamps.

Life span of Incandescent and CFL

Incandescent: The Incandescent lamp has a life span of 1000hours (see Table 1)

No. of hours used daily $=9$ hours

No. of days of use

$$
=\frac{1000}{9}
$$

This is equivalent to approximately 4 months.

CFL: The CFL has a life span of 5000 hours

No. of hours used daily $=9$ hours

No. of days of use

$=\frac{5000}{9}$

This is equivalent to approximately 18 months.

The above calculations indicate that an incandescent lamp may be replaced about five times before a CFL is replaced.

The replacement of an Incandescent lamp compared with the life span of CFL will cost approximately $\$ 12,500$, that is $5 \times \$ 2,500$. The Electricity Company sells one CFL at $\$ 11,250$. Thus, considering the cost involved in the replacement of Incandescent lamps vis-à-vis CFL, it would be more expensive to rely on Incandescent lamps.

However, it would be more expensive to buy CFL from the open market as it sells between $\$ 20,000$ and $\$ 28,000$.

\section{Cost of electricity consumption between Incandescent and CFL}

The calculations were based on the following:

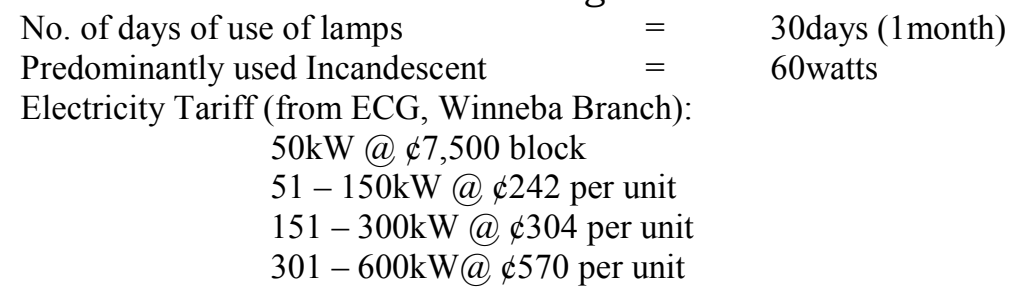

Incandescent:

Energy consumption, $\quad \mathrm{E}_{\mathrm{c}}=\mathrm{Pt}$ (where $\mathrm{P}$ is Power, and $\mathrm{t}$ is time of use of electricity)

$=60 \times 10^{-3} \times 9 \times 30 \mathrm{kWh}$

$=\quad 16.2 \mathrm{kWh}$ 


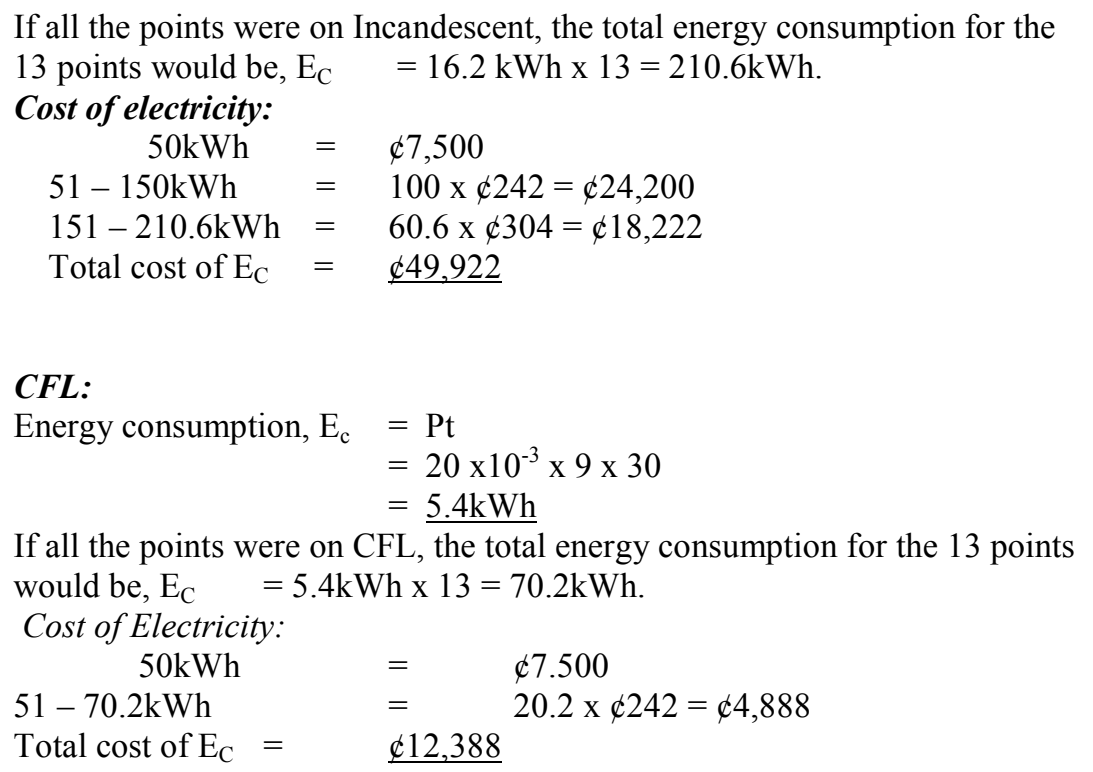

Comparing the consumption rates of energy for the two lamps, it is observed that in one month, CFL consumes far less than the Incandescent lamp $(70.2 \mathrm{kWh}$ as against $210.6 \mathrm{kWh})$. It can therefore be concluded that the CFL can be used as an energy saving device. Again, considering the cost of consumption of the two lamps the use of CFL is cost-effective. It clearly shows that even if the CFL is bought at the open market at $\$ 28,000$, it will still be cheaper.

\section{Conclusion}

The study clearly shows that consumers prefer lighting systems that are less expensive (i.e. Incandescent). This observation is in agreement with the statement made earlier that the economic base of Ghanaians and the seemingly high cost of efficient lighting systems compel the average Ghanaian to go in for lighting systems that are less expensive.

It was observed that even though $82 \%$ of the respondents have obtained information and therefore have knowledge of CFLs, and $72 \%$ know that CFLs serve as energy saving device, only 3\% use CFLs. It is important to mention here that $69.7 \%$ of those who use CFLs opted to pay cash directly than to pay for the cost of CFL through electricity bills, the main reason being that, very often, bills sent to consumers are unreliable. Sometimes, estimated electricity bills are sent to consumers. Considering the long-term benefits, CFLs serve as energy saving device. The additional advantage is the reduction in the cost of energy consumption, that is, the use of CFLs help in cutting down electricity bills.

\section{Recommendations}

Based on the observations made above the following recommendations have been made:

1. There is the need for the government to help in lowering the cost of CFL. One way by which this could be done is to reduce the tax element on the importation of CFLs. 
2. The utility companies must ensure that information on the use of CFLs includes financial incentives such as providing discount facilities to the low income groups to enable them patronise the use of CFLs.

3. There should be clear direction and comprehensive policy from the central and local governments on the use of CFLs as energy saving device.

4. The true cost of electricity consumption must reflect on the bills without subsidy from the government. This will create the awareness of the need to conserve energy and so make the use of CFLs quite attractive.

5. The Electricity Company must ensure that more reliable bills are sent to consumers to enable them know their energy consumption pattern. The company should also be made the sole agent for the sale of CFL to attract its use.

6. The Electricity Company should intensify its educational programs on the use of CFLs.

\section{References}

Barelett, S. (1993): Energy, The International Journal 18, 171.

Brond E. (1990): The NESA All-Sector Light Programme: Results and Analysis from a Full-Scale Campaign in 1990 for the propagation of Compact Fluorescent Lamps, Ref. 20.

Johansson T. B., Bodlund B and Williams R. H. (1989): Electricity: Efficient End-Use and New Generation Technologies and Their Planning Implications, Lund University Press, Lund, Sweden.

Mills E. (1996): Energy Efficiency: No-Regrets Climate Change Insurance Industry. Journal of the Society of Insurance Research, Vol. 9, No.3 (Fall), pp. 21-58.

Min G. F., Mills E. and Zhang Q. (1997): Energy Efficient Lighting in China. Energy Policy, Vol. 25, No. 1 pp. 80, Copyright - Elsevier Science Ltd.

Page E., Mills E. and Siminovitch M. (1997): New Energy Efficient Torchieres Ready for Hot Torchiere Market, Proceedings of Energy Efficiency in Household Appliance Workshop, Florence, Italy. Published by the European Commission, Lawrence Berkley National Laboratory Report No. 41176. 